\title{
THE PROGNOSTIC SIGNIFICANCE OF DEPERSONALIZATION IN DEPRESSIVE ILLNESSES TREATED WITH ELECTROCONVULSIVE THERAPY
}

\author{
BY \\ BRIAN ACKNER and Q. A. F. R. GRANT* \\ From Bethlem Royal Hospital and the Maudsley Hospital, London \\ STATISTICAL APPENDIX \\ BY \\ A. E. MAXWELL \\ From the Institute of Psychiatry, London
}

\begin{abstract}
Earlier Views
Before the introduction of electroconvulsive therapy it was a generally accepted view that a depressive illness which was accompanied by symptoms of depersonalization was likely to run a long course. In recent years, however, opinions on the prognostic significance of depersonalization in depressive illness have been more divided.

Mayer-Gross, Slater, and Roth (1954) stated that the presence of depersonalization indicated a more prolonged illness, and Lewis (1956) continued to take this view which he had expressed much earlier (Lewis, 1936). Ackner (1954) found that, in contrast to other depersonalization syndromes, the depressive depersonalization syndrome often responded favourably to electroconvulsive therapy (E.C.T.). Sargant and Slater (1954) expressed the opinion that although the depression may be cleared up by E.C.T., the depersonalization often remains. More recently, Roth (1959) has claimed that in the presence of depersonalization E.C.T. is contraindicated in a depressive illness.
\end{abstract}

\section{Nature of the Present Investigation}

No study appears to have been reported so far in which the outcome of treatment with E.C.T. in depressives with depersonalization has been compared with the outcome in a similarly treated matched control group of depressives free from depersonalization symptoms. The present study reports the results of such an investigation.

*Director, Child Psychiatric Unit, Jewish Hospital, St. Louis, Missouri, U.S.A.
The patients in this study had all been in-patients at the Maudsley Hospital. During a seven-year ${ }_{\mathcal{E}}$ period 50 patients suffering from depression aø $\omega$ companied by depersonalization were found have been treated by E.C.T. (It is probable the more such cases were so treated during this periog and were not found, but their omission can be cot sidered to be random in nature.)

Of the 50 patients, 23 were considered to suffering from a clear-cut endogenous type of illne as judged by the usual criteria, e.g., retardation $\overrightarrow{\mathrm{y}} \overrightarrow{\mathrm{\theta}}$ severe agitation, diurnal variation, severe weight loss, early morning waking, delusions of self- 0 reproach and unworthiness, auditory hallucinations with a depressive content, absence of significant external stresses, etc. Nineteen cases were con-

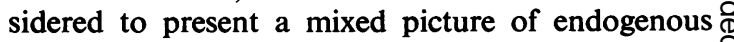

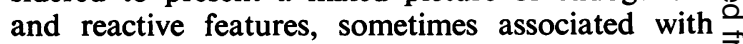
obsessive, hysterical, or anxiety symptoms. Of the remaining eight patients, two were considered to be of an endogenous type but as all had certain features which made it difficult to find a suitable matching control case, they were kept as a separate atypical group.

\section{Method of Matching for Control Cases}

Each patient in the endogenous and mixed group was separately matched with a suitable control case which had been treated by E.C.T. for a depressive illness not 을 accompanied by depersonalization symptoms. In considering the suitability of a control case for matching, $\frac{7}{0}$ the following features were taken into account.

Type of Depressive Illness. - If matching with a patient $N$ from the endogenous group, the control case must have $N$ had similar presenting features. A case with prominent 
retardation would be matched with another retarded control case and similarly for agitation, paranoid ideas, delusions of guilt, hypochondriasis, etc. If matching with a patient from the mixed group, the control case must have had corresponding features where these were prominent, e.g., anxiety, obsessional, hysterical, reactive factors, etc.

Sex.-Each case was matched with a control of the corresponding sex.

Age.-Each case was matched with a control whose age was in the same one of five groups: 20-30, 30-40, 40-50, 50-60, 60-70.

Duration of Symptoms. - Each case was matched with a control in whom the duration of symptoms before treatment was in the same one of five groups: 0-1 month, 1-6 months, 6-12 months, 1-2 years, over 2 years.

Admission Epoch.-In finding a suitable matching control an attempt was made to ensure as far as possible that each pair had been admitted within 18 months of each other. This was achieved in the majority of cases and in only two cases was the admission interval greater than three years.

Personality.-Cases were matched for prominent personality features such as obsessional, hysterical, immature or dependent, shy or withdrawn, over-sensitive or paranoid, aggressive, etc.

Previous Depressive Attacks. - Within the limits of the number of cases available it was not possible to match each case with another control case with an exactly similar history of previous depressive attacks. However, the history of previous depressions in both groups as a whole were essentially comparable.

TABLE I

NUMBER OF PREVIOUS DEPRESSIVE ILLNESSES

\begin{tabular}{l|c|c|c|c}
\hline $\begin{array}{c}\text { Previous Depressive } \\
\text { Illness }\end{array}$ & $\begin{array}{c}\text { Endogenous Group } \\
\begin{array}{c}\text { Deper- } \\
\text { Sonalized } \\
(23 \text { Cases) }\end{array}\end{array}$ & $\begin{array}{c}\text { Montrols } \\
\text { (23 Cases) }\end{array}$ & $\begin{array}{c}\text { Meper- } \\
\text { sonalized } \\
\text { (19 Cases) }\end{array}$ & $\begin{array}{c}\text { Controls } \\
\text { (19 Cases) }\end{array}$ \\
\hdashline None & 6 & 9 & 10 & 12 \\
One & 9 & 10 & 5 & 4 \\
Two & 5 & 3 & 3 & 2 \\
Three or more & 3 & 1 & 1 & 1 \\
\hline
\end{tabular}

Of the 23 endogenous cases in each of the depersonalized and control groups, 22 were female and one male. The mean age of the endogenous depersonalized group was $41 \cdot 2$ years (S.D. 12.2) and that of the endogenous control group 41.8 years (S.D. 13.9). Of the 19 mixed cases in each of the depersonalized and control groups, 17 were female and two male. The mean age of the mixed depersonalized group was 34.8 years (S.D. 9.4) and that of the mixed control group 35 years (S.D. 10.0). Of the eight atypical depersonalized cases, five were female and three male, the mean age being $29 \cdot 1$ (S.D. 5.9).

\section{Response of Depressive Symptoms to E.C.T.}

The outcome of treatment in each case was assessed according to the following criteria. (a) Clinical response to course of E.C.T. rated as recovered, much improved, somewhat improved, no change, or worse; (b) number of E.C.T. given; (c) further course of E.C.T. if required; $(d)$ weeks spent in hospital after completion of E.C.T.; (e) condition on discharge; $(f)$ relapse within three months of completion of first course of E.C.T.

\section{Results}

Depressive Symptoms.-The response of the depressive symptoms to E.C.T. is presented in Tables II and III, and the results of the statistical analysis of the detailed figures are presented in the Appendix. It will be seen that both for the endogenous and the mixed groups there is no significant difference between the depersonalized and the control cases in the immediate response to E.C.T., in the number of cases requiring a further course of E.C.T., or in the condition on discharge from hospital. There is also no significant difference in the average number of electroconvulsive treatments required to reach the same degree of clinical improvement in the depersonalized and control cases both in the endogenous and in the mixed groups. This is shown most clearly when those pairs in which both cases were recovered or were much improved were examined for the number of E.C.T. required (see Appendix). This method also reveals no significant difference between the depersonalized and control cases in both groups for the duration of stay in hospital after completion of E.C.T. in those cases which, after E.C.T., were recovered or much improved (see Appendix).

The figures (mean values in Table II) for duration of stay in hospital after completion of the first course of E.C.T. require more detailed consideration. In both the depersonalized and control cases of the endogenous group those patients who were much improved stayed after treatment an average of 16.3 and 13.3 weeks respectively. These are surprisingly high figures but they appear to be accounted for by three depersonalized and three control patients all of whom relapsed, required further E.C.T., and stayed respectively an average of 28.3 and 30.3 weeks after the completion of the first course of E.C.T. In those patients who were only somewhat improved or unchanged after E.C.T. the duration of stay in hospital appears to be higher in the depersonalized cases in both the endogenous and mixed groups. Although these figures are partly accounted for by a few very long-stay patients in both groups (e.g., one depersonalized patient of the endogenous group stayed 52 weeks and one depersonalized patient of the mixed group stayed 41 weeks) there is a suggestion that depersonalization may prolong the stay in those patients who do not recover with E.C.T. This possibility will be 
TABLE II

RESPONSE OF DEPRESSIVE SYMPTOMS TO E.C.T.

\begin{tabular}{|c|c|c|c|c|}
\hline & \multicolumn{2}{|c|}{ Endogenous Group } & \multicolumn{2}{|c|}{ Mixed Group } \\
\hline & $\begin{array}{l}\text { Depersonalized } \\
\text { (23 Cases) }\end{array}$ & $\begin{array}{c}\text { Controls } \\
\text { (23 Cases) }\end{array}$ & $\begin{array}{l}\text { Depersonalized } \\
\text { (19 Cases) }\end{array}$ & $\begin{array}{c}\text { Controls } \\
\text { (19 Cases) }\end{array}$ \\
\hline $\begin{array}{l}\text { Response to First Course of E.C.T. } \\
\text { Number of cases recovered } \\
\text { Average number of E.C.T. } \\
\text { Average weeks in hospital after first course of E.C.T. }\end{array}$ & $\begin{array}{l}9 \\
8 \\
2 \cdot 8\end{array}$ & $\begin{array}{l}7 \\
6 \cdot 7 \\
3 \cdot 1\end{array}$ & $\begin{array}{r}5 \\
10 \cdot 2 \\
4 \cdot 2\end{array}$ & $\begin{array}{l}4 \\
6 \cdot 5 \\
2 \cdot 8\end{array}$ \\
\hline $\begin{array}{l}\text { Number of cases much improved } \\
\text { Average number of E.C.T. } \\
\text { Average weeks in hospital after first course of E.C.T. }\end{array}$ & $\begin{array}{l}7 \\
8 \\
16 \cdot 3\end{array}$ & $\begin{array}{r}12 \\
7 \cdot 4 \\
13 \cdot 3\end{array}$ & $\begin{array}{l}7 \\
7 \cdot 6 \\
6\end{array}$ & $\begin{array}{l}6 \\
6 \cdot 8 \\
7\end{array}$ \\
\hline $\begin{array}{l}\text { Number of cases somewhat improved or no change } \\
\text { Average number of E.C.T. } \\
\text { Average weeks in hospital after first course of E.C.T. }\end{array}$ & $\begin{array}{r}7 \\
7 \cdot 6 \\
18 \cdot 3\end{array}$ & $\begin{array}{l}4 \\
6 \cdot 5 \\
7 \cdot 3\end{array}$ & $\begin{array}{r}7 \\
9 \cdot 3 \\
13 \cdot 1\end{array}$ & $\begin{array}{l}9 \\
6 \cdot 1 \\
9 \cdot 4\end{array}$ \\
\hline $\begin{array}{l}\text { Number of Cases Requiring Further Course of E.C.T. } \\
\text { One more course } \\
\text { Two more courses }\end{array}$ & $\begin{array}{l}8 \\
0\end{array}$ & $\begin{array}{l}6 \\
1\end{array}$ & $\begin{array}{l}1 \\
1\end{array}$ & $\begin{array}{l}\mathbf{0} \\
\mathbf{0}\end{array}$ \\
\hline $\begin{array}{l}\text { Condition on Discharge Compared with Post-E.C.T. State } \\
\text { Remaining recovered or much improved } \\
\text { Remaining somewhat improved or unchanged } \\
\text { Better than post-E.C.T. condition on discharge } \\
\text { Worse than post-E.C.T. condition on discharge }\end{array}$ & $\begin{array}{r}14 \\
2 \\
5 \\
2\end{array}$ & $\begin{array}{r}15 \\
1 \\
3 \\
4\end{array}$ & $\begin{array}{r}11 \\
6 \\
1\end{array}$ & $\begin{array}{l}9 \\
5 \\
4 \\
1\end{array}$ \\
\hline $\begin{array}{l}\text { Final Condition on Discharge } \\
\text { Recovered } \\
\text { Much improved } \\
\text { Somewhat improved or unchanged }\end{array}$ & $\begin{array}{r}15 \\
4 \\
4\end{array}$ & $\begin{array}{r}11 \\
7 \\
5\end{array}$ & $\begin{array}{l}5 \\
7 \\
7\end{array}$ & $\begin{array}{l}6 \\
7 \\
6\end{array}$ \\
\hline
\end{tabular}

considered in more detail in the following section.

The number of those patients who had recovered or improved with E.C.T. but whose symptoms relapsed within three months of the first treatment is shown in Table III. (Some of the cases were

TABLE III

RELAPSE OF DEPRESSIVE SYMPTOMS WITHIN THREE MONTHS OF FIRST TREATMENT IN CASES RECOVERED OR IMPROVED WITH E.C.T.

\begin{tabular}{c|c|c|c}
\hline Endogenous Group & \multicolumn{2}{|c}{ Mixed Group } \\
\hline $\begin{array}{c}\text { Depersonalized } \\
\text { (16 Cases) }\end{array}$ & $\begin{array}{c}\text { Controls } \\
\text { (19 Cases) }\end{array}$ & $\begin{array}{c}\text { Depersonalized } \\
\text { (12 Cases) }\end{array}$ & $\begin{array}{c}\text { Controls } \\
\text { (10 Cases) }\end{array}$ \\
\hline 6 & 7 & 5 & 3 \\
\hline
\end{tabular}

given further E.C.T.) The numbers are too small for statistical treatment but reveal little difference between the depersonalized and control cases either in the endogenous or mixed groups.

Depersonalization Symptoms.-Of the eight unmatched depersonalized cases two were endogenous and six were mixed in type. These, added to the other depersonalization cases, made a total of 25 patients in each of the endogenous and mixed depersonalization groups. In Table IV it will be seen that in the endogenous compared with the mixed group a significantly greater number of patients have lost their depersonalization symptoms both after a course of E.C.T. and at the time of discharge from hospital. Seventy-six per cent. of the endogenous group lost their symptoms after
TABLE IV

RESPONSE OF DEPERSONALIZATION SYMPTOMS TO E.C.T.

\begin{tabular}{|c|c|c|c|c|}
\hline & \multicolumn{2}{|c|}{$\begin{array}{l}\text { Endogenous Group } \\
\text { (25 Cases) }\end{array}$} & \multicolumn{2}{|c|}{$\begin{array}{l}\text { Mixed Group } \\
\text { (25 Cases) }\end{array}$} \\
\hline & $\begin{array}{c}\text { After } \\
\text { First } \\
\text { Course } \\
\text { of E.C.T. }\end{array}$ & $\underset{\text { Discharge }}{\text { At }}$ & $\begin{array}{c}\text { After } \\
\text { First } \\
\text { Course } \\
\text { of E.C.T. }\end{array}$ & $\begin{array}{c}\text { At } \\
\text { Dischard }\end{array}$ \\
\hline $\begin{array}{l}\text { Recovered } \\
\text { Much improved } \\
\text { Somewhat improved } \\
\text { No change } \\
\text { Worse }\end{array}$ & $\begin{array}{r}19 \\
1 \\
0 \\
5 \\
0\end{array}$ & $\begin{array}{r}21 \\
1 \\
1 \\
2 \\
0\end{array}$ & $\begin{array}{r}10 \\
0 \\
5 \\
9 \\
1\end{array}$ & $\begin{array}{r}10 \\
3 \\
6 \\
6 \\
0\end{array}$ \\
\hline
\end{tabular}

E.C.T. compared with $40 \%$ in the mixed group.

In Table $\mathbf{V}$ it will be seen that there was a larger number of cases in the mixed group in which, compared with the depressive symptoms, the depersonalization symptoms responded poorly. Table VI reveals that there was a somewhat larger number of cases in the endogenous group in which after E.C.T. the depersonalization symptoms had disappeared and some depressive symptoms still remained.

TABLE $V$

NO. OF CASES IN WHICH AFTER E.C.T. THE DEPRESSION RECOVERED OR WAS MUCH IMPROVED AND DEPERSONALIZATION LITTLE IMPROVED, UNCHANGED, OR WORSE

\begin{tabular}{l|c|c|}
\hline & $\begin{array}{c}\text { Endogenous Group } \\
\text { (25 Cases) }\end{array}$ & $\begin{array}{c}\text { Mixed Group } \\
\text { (25 Cases) }\end{array}$ \\
\hline $\begin{array}{l}\text { After E.C.T. } \\
\text { On discharge }\end{array}$ & 2 & 10 \\
\hline
\end{tabular}


TABLE VI

NO. OF CASES IN WHICH AFTER E.C.T. DEPERSONALIZATION SYMPTOMS DISAPPEARED AND SOME DEPRESSIVE SYMPTOMS REMAINED

\begin{tabular}{l|c|c}
\hline & $\begin{array}{c}\text { Endogenous Group } \\
\text { (25 Cases) }\end{array}$ & $\begin{array}{c}\text { Mixed Group } \\
\text { (25 Cases) }\end{array}$ \\
\hline After E.C.T. & 9 & 3 \\
On discharge & 5 & 3 \\
\hline
\end{tabular}

The relationship of the continued presence of depersonalization symptoms after E.C.T. to the duration of stay in hospital merits further consideration. From Table IV it will be seen that there were five patients in the endogenous depersonalization group in whom the depersonalization symptoms were unimproved after E.C.T. (though only one patient in whom the depression was unimproved). No cases in this group were "somewhat improved". These five patients stayed in hospital an average of 23.8 weeks after completion of the first course of E.C.T. (11, 18, 19, 19, and 52 weeks). In the endogenous control group there was one patient in whom the depression was unimproved after E.C.T. and this patient stayed only eight weeks after completion of E.C.T. There were three further patients in the endogenous control group in whom the depression was only somewhat improved by E.C.T. and they subsequently remained an average of seven weeks in hospital. From Table V it will also be seen that there were 10 patients in the mixed depersonalization group in whom the depersonalization was unimproved or worse after E.C.T. These 10 patients stayed an average of 13.5 weeks in hospital after completion of the first course of E.C.T. (one, four, five, five, 10, 12, 13, 22, 22, and 41 weeks). In the mixed control group there were three patients who were unimproved or worse after E.C.T. and these stayed an average of 12 weeks after completion of E.C.T. (six, 14, and 16 weeks). Taking all the patients who were somewhat improved, unimproved, or worse as regards the depersonalization in the mixed group, there were 15 staying an average of 10 weeks after E.C.T. In the mixed control group there were nine patients in whom the depression was somewhat improved, unimproved, or worse after E.C.T., and these stayed an average of 9.5 weeks after E.C.T. These numbers are small but they suggest that, compared with the nondepersonalized depressive who is unimproved by E.C.T., the continued presence of depersonalization symptoms after E.C.T. betokens a longer stay in hospital in the endogenous, but not in the mixed type of case.

\section{Discussion}

It has been suggested by a number of previous authors that the presence of depersonalization in a depressive illness indicates a more prolonged course and that E.C.T. may benefit the depersonalization little or may make it worse.

Our results show that as regards depressive symptoms, depersonalized depressives treated with E.C.T. recovered or improved to the same extent, needed the same amount of E.C.T., and stayed as long in hospital as did carefully matched controls similarly treated. Depersonalization symptoms responded favourably to E.C.T. in those depressives whose clinical picture was clearly endogenous in type. On the other hand the response of the depersonalization to E.C.T. was much less favourable in those depressives in whom neurotic symptoms or reactive features were part of the clinical picture. In such cases the depersonalization was often unchanged and in one case was made temporarily worse. Furthermore, there is a suggestion that in those endogenous cases in which depersonalization symptoms do not clear up with E.C.T., the stay in hospital may be prolonged.

Ackner (1954) pointed out the importance of distinguishing those depressed patients whose depersonalization was on the basis of depressive loss of affect from those depressed patients in whom the depersonalization arose from hysterical, tension, or other factors, claiming that E.C.T. benefited the former but often not the latter. The present more detailed and controlled study confirms these views.

\section{Summary}

Depressed patients suffering from depersonalization who had been treated with E.C.T. were matched with depressed patients not suffering from depersonalization who had also been treated with E.C.T. Each case was separately matched for type of illness, sex, age, duration of symptoms, admission epoch, and personality. No significant differences between the groups were found as regards the response of the depressive symptoms to E.C.T., the number of courses of E.C.T. required, the duration of stay in hospital, or the relapse rate. In those depressions which were of a clear-cut, endogenous type the depersonalization usually cleared up with E.C.T. but in other types of depression the response was often less favourable.

\section{REFERENCES}

Ackner, B. (1954). J. ment. Sci., 100, 854.

Lewis, A. (1936). Lancet, 2, 997.

(1956). In Price's Textbook of Medicine, 9th ed., ed. D. Hunter, p. 1653. Oxford Univ. Press, London.

Mayer-Gross, W., Slater, E., and Roth, M. (1954). Clinical Psychiatry, p. 207. Cassell, London.

Roth, M. (1959). Proc. roy. Soc. Med., 52, 587.

Sargant, W., and Slater, E. (1954). An Introduction to Physical Methods of Treatment in Psychiatry, 3rd ed., p. 87. Living-

Stuart, A. (1957). Brit. J. stat. Psychol., 10, 29. 


\section{S T A T IS T I CALA P P E N D IX}

When comparing the frequencies of depersonalized and control patients given in Table II, straightforward $\chi^{2}$ tests are not appropriate since the patients in the two categories, having been matched, are not independent. As a result resort was had to a method devised by Stuart (1957) for comparing frequencies in matched samples. To apply this method the data for both the endogenous and the mixed groups were arranged in fourfold tables. In the case of the endogenous group, if the numbers of patients who "recovered" are compared with the remainder, the fourfold table is:

\begin{tabular}{c|c|c|c}
\hline & Recovered & Remainder & Total \\
\hline $\begin{array}{l}\text { Depersonalized patients } \\
\text { Controls }\end{array}$ & $\begin{array}{c}9(\mathrm{a}) \\
7 \text { (c) }\end{array}$ & $\begin{array}{c}14(\mathrm{~b}) \\
16(\mathrm{~d})\end{array}$ & 23 \\
\hline \multicolumn{1}{|c|}{ Total } & 16 & 30 & 46 \\
\hline
\end{tabular}

If the numbers of patients "recovered" or "much improved" are compared with the remainder the fourfold table is:

\begin{tabular}{c|c|c|c}
\hline & $\begin{array}{c}\text { Recovered } \\
\text { or Much } \\
\text { Improved }\end{array}$ & Remainder & Total \\
\hline $\begin{array}{c}\text { Depersonalized patients } \\
\text { Controls }\end{array}$ & 16 (a) & $\begin{array}{c}7 \text { (b) } \\
4 \text { (d) }\end{array}$ & 23 \\
\hline Total & 35 & 11 & 46 \\
\hline
\end{tabular}

The number (S) of matched pairs in which both patients recovered is now ascertained. For the first fourfold table $\mathbf{S}$ was found to be 2; for the second $\mathbf{S}$ was found to be 14. Stuart's test then requires us to calculate the statistic $Y$ given by the expression:

$$
Y=\frac{|a-c|-0.5}{\sqrt{a+c-2 S}}
$$

and to refer the result to the normal distribution. The values of $Y$ given by this formula for the respective fourfold tables are 0.434 and 0.884 which are well below the value of 1.96 required for significance at the $5 \%$ level, so we may safely conclude that for the endogenous group the frequencies given in the fourfold tables for depersonalized patients and for controls do not differ.

The frequencies in Table II for the mixed group were compared in a similar manner and again no significant differences between depersonalized patients and controls were found.

The average number of electroconvulsive treatments administered to the 14 pairs of patients in the endogenous group who recovered or were much improved after the first course of treatment were compared by a $t$ test for correlated means. The value of $t$ was found to be 1.24 which, with 13 degrees of freedom, does not reach an accepted level of significance. We conclude that there is no significant difference in the average number electroconvulsive treatments required to reach the same degree of clinical improvement in the depersonalized and control patients.

In the case of the mixed group eight pairs of matched patients recovered or were much improved after the first course of E.C.T. The average numbers of electroconvulsive treatments for depersonalized and control patients were again compared by a $t$ test. The value of $t$ was found to be 2.27 which is below the $5 \%$ significanc level.

The average number of weeks in hospital for the 14 matched pairs in the endogenous group and the eight matched pairs in the mixed group, who were recovered or much improved after the first course of treatment, were also compared by $t$ tests for correlated means but no significant differences were found.

For the other comparisons mentioned in the text the results are either obvious or the sample sizes are too small to merit treatment by statistical methods. 